\title{
Incremental cost-effectiveness of dobutamine stress cardiac magnetic resonance imaging in patients at intermediate risk for coronary artery disease
}

\author{
George Petrov • Sebastian Kelle • Eckart Fleck • \\ Ernst Wellnhofer
}

Received: 30 July 2014/Accepted: 10 November 2014/Published online: 14 November 2014

(C) The Author(s) 2014. This article is published with open access at Springerlink.com

\begin{abstract}
Aims The effectiveness of stress cardiac magnetic resonance (CMR) as a gatekeeper for coronary angiography (CA) has been established. Level five HTA studies according to the hierarchical model of diagnostic test evaluation are not available.

Methods This cohort study included 1,158 consecutive patients (mean age $63 \pm 11$ years, $42 \%$ women) presenting at our institution between January 1, 2003 and December 31, 2004 with suspected coronary artery disease (CAD) for an elective CA. The patients were assessed for eligibility and propensity score matching was applied to address selection bias regarding the patients' allocation to CMR or direct CA. Median patient follow-up was 7.9 years (95\% CI 7.8-8.0 years). The primary effect was calculated as relative survival difference. The cost unit calculation (per patient) at our institute was the source of costs.

Results Survival was similar in CMR and CA $(p=0.139)$. Catheterizations ruling out CAD were significantly reduced by the CMR gate-keeper strategy. Patients with prior CMR had significantly lower costs at the initial hospital stay and at follow-up (CMR vs. CA, initial: $2,904 €$ vs. $3,421 €, p=0.018$; follow-up: $2,045 €$ vs. $3,318 €, p=0.037)$. CMR was cost-effective in terms of a
\end{abstract}

G. Petrov and S. Kelle contributed equally to this work.

Electronic supplementary material The online version of this article (doi:10.1007/s00392-014-0793-0) contains supplementary material, which is available to authorized users.

G. Petrov $\cdot$ S. Kelle $\cdot$ E. Fleck $\cdot$ E. Wellnhofer $(\bowtie)$

Department of Internal Medicine/Cardiology, German Heart Institute Berlin, Augustenburger Platz 1, 13353 Berlin, Germany

e-mail: wellnhofer@dhzb.de contribution of $12,466 €$ per life year to cover a part of the CMR costs.

Conclusion Stress CMR prior to CA was saving 12,466€ of hospital costs per life year. Lower costs at follow-up suggest sustained cost-effectiveness of the CMR-guided strategy.

Keywords Cost-effectiveness analysis $\cdot$ Stress $\cdot$ Magnetic resonance imaging - Coronary angiography · Coronary artery disease

$\begin{array}{ll}\text { Abbreviations } \\ \text { CA } & \text { Coronary angiography } \\ \text { CAD } & \text { Coronary artery disease } \\ \text { CABG } & \text { Coronary artery bypass graft } \\ \text { CI } & \text { Confidence interval } \\ \text { CMR } & \text { Cardiac magnetic resonance } \\ \text { CV } & \text { Cardiovascular } \\ \text { HR } & \text { Hazard ratio } \\ \text { HTA } & \text { Health technology assessment } \\ \text { ICER } & \text { Incremental cost-effectiveness ratio } \\ \text { LV } & \text { Left ventricular } \\ \text { PCI } & \text { Percutaneous coronary intervention } \\ \text { DRG } & \text { Diagnose related groups } \\ \text { InEK } & \text { Institut für das Entgeltsystem im Krankenhaus } \\ & \text { (Agency for calculation of reimbursement of in- } \\ & \text { hospital treatment) }\end{array}$

\section{Introduction}

The management of stable patients with suspected coronary artery disease (CAD) is guided by history and 
evidence of stress-induced myocardial ischemia. The diagnostic accuracy of a stress test varies, depending upon the age, gender and clinical characteristics of the patient, prevalence of CAD in the demographic examined, and modality of the test used. In particular stress imaging is superior to exercise electrocardiogram [1]. The diagnostic accuracy of stress cardiac magnetic resonance (CMR) was found to be higher than stress echocardiography and single photon emission tomography [2-4]. Dobutamine stress CMR (DCMR) is an accurate and safe non-invasive test with high negative predictive value $[4,5]$. Several recent long-term follow-up studies demonstrate the safety of a deferral of catheterization in case of negative DCMR [6-8]. Direct catheterization (CA) is still a competitive approach, however, at least in patients with intermediate cardiovascular risk and ambiguous stress electrocardiograms.

CA is still incentivized by the current reimbursement policy in Germany and many other countries. Since longterm outcome and cost data from randomized controlled prospective trials are rarely available when new health technologies emerge, evidence-based reimbursement policy requires retrospective data mining and lags behind medical and technical evolution [9]. High-quality observational data models, simulations and other techniques are commonly used in health technology assessment (HTA) $[10,11]$. Studies vary widely regarding imaging modality, methodological approach, control groups and outcome measures and generally adopt the stakeholder perspective of the payer $[12,13]$. Moreover, no level five HTA studies according to the hierarchical model of diagnostic test evaluation [14] have been published hitherto.

This paper presents level five HTA data on DCMR based on a long-term follow-up of patients with suspected stable CAD (sCAD) who underwent DCMR and controls with direct CA. We expected that a DCMR-guided approach would be at least as effective as direct CA with respect to survival and more patient-friendly in terms of fewer hospitalizations during follow-up by avoiding direct $\mathrm{CA}$, which is known to have a low diagnostic yield in a routine setting [15].

\section{Methods}

This retrospective cohort study is a controlled comparison of two different pathways for managing patients with sCAD and intermediate event risk. The term "intermediate event risk" refers to the risk of annual all-cause mortality of $\geq 1$ but $\leq 3 \%$ as suggested by the guidelines on the management of SCAD [16]. The source population includes 1,158 consecutive patients referred to the German Heart Institute Berlin between January 1, 2003 and December 31, 2004. Inclusion criteria were SCAD and sufficient data on age, gender, symptoms, cardiovascular (CV) risk factors and medical therapy. Exclusion criteria were known CAD verified by previous angiography, LV ejection fraction $(\mathrm{LVEF}) \leq 40 \%$, history of cardiac transplantation or an indication different from SCAD for CA. Finally, 843 eligible patients were adjusted for selection bias by propensity score matching and 502 patients remained (CMR: 209 pts. vs. CA: 293 pts.; Fig. 1). The study was approved by the Charite University Hospital Ethics Committee and complies with the principles outlined in the Declaration of Helsinki.

The clinical data were collected from institutional quality assurance and research databases. Missing data were gathered by hospital chart review. The costs data were calculated per patient and hospital stay according to the requirements of the German federal InEK/G-DRG database. Since the InEK calculation was first introduced in 2004 and subsequently modified in 2008 , cost data were available in the years 2004-2008 only. The cost calculation method was cost unit accounting based on real processes and expenditures per hospitalized patient. In terms of clean methodology we chose cost contribution accounting as a method to compare both approaches. Discounting or inflation correction was not performed.

Median patient follow-up was 7.9 years $(95 \%$ CI 7.8-8.0 years). Primary clinical endpoints were death and the occurrence of cardiac re-hospitalizations. Revascularization by percutaneous coronary intervention (PCI) or coronary artery bypass grafting (CABG) was not treated as endpoint but as covariate to control for its potential impact on survival and costs. Before the study database was closed in December 2011, a query in the digital medical archive was performed to assign unknown deaths and the number of cardiac re-hospitalizations during the entire observation period.

DCMR was performed according to the recommendations of the Society for Cardiovascular Magnetic Resonance [17] using a balanced, fast-field echo sequence with parallel imaging. The imaging methodology has been described in detail previously $[6,18]$. Myocardial ischemia was defined as an induced wall motion abnormality or a biphasic response in $\geq 1$ segments of the left ventricle during infusion of dobutamine. Images were analyzed during and immediately after the examination by two experienced investigators without post-processing [6].

The statistical analysis was performed using IBM SPSS Statistics, version 21, and R, version 2.14.2. Clinical data in the tables are presented as mean $\pm \mathrm{SD}$ or percentages and the cost data as median costs $(95 \% \mathrm{CI})$ unless otherwise indicated. Effect estimates were calculated by subtracting the individual event-free survival from the median event-free survival and dividing the difference by the median event-free survival and cost estimates by 
Fig. 1 Patient selection. 1,158 consecutive patients referred with suspected SCAD were assessed for eligibility. 843 patients of them remained after exclusion of factors, known to affect the CMR/CA allocation, and were adjusted on their risk probability for CAD by propensity score matching. After matching 502 patients at comparable risk were enrolled. Asterisk matching variables: age, gender, LVEF, angina pectoris, hypertension, hyperlipidemia, diabetes mellitus, smoking, ACE inhibitors, $\beta$ blockers, calcium channel inhibitors, statins. $L V E F$ left ventricular ejection fraction, $A C E$ angiotensin converting enzyme

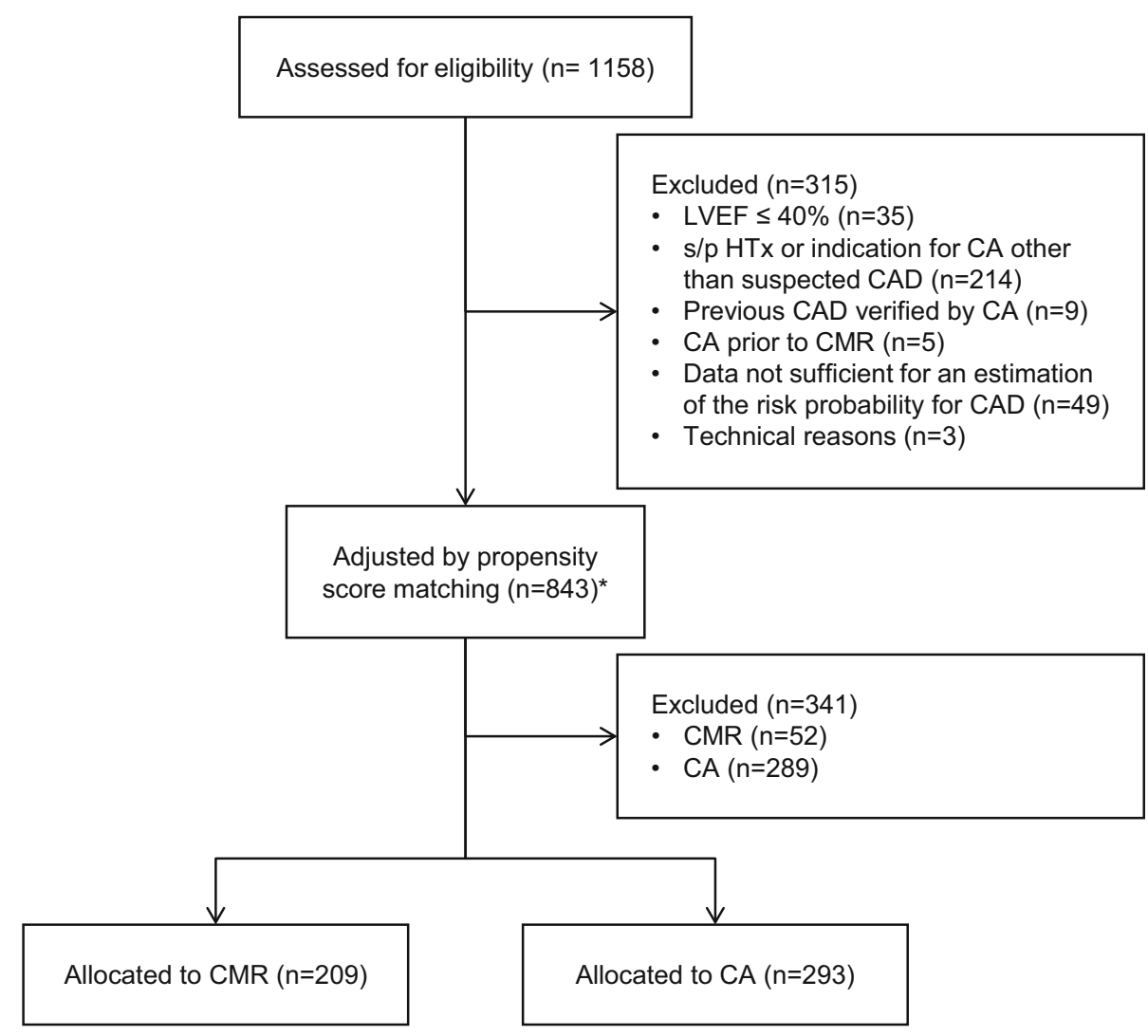

subtracting the individual costs from the median costs and dividing the difference by the median costs. Incremental cost-effectiveness ratio (ICER) was calculated as.

$\mathrm{ICER}=\left[\frac{\text { median costs }_{\mathrm{CMR}}-\text { median costs }_{\mathrm{CA}}}{\text { median survival }_{\mathrm{CMR}}-\text { median survival }_{\mathrm{CA}}}\right]$

and expressed as median cost savings per life year. Unpaired $t$ test or Mann-Whitney $U$ test were used to compare groups. Categorical variables were tested using Pearson's $\chi^{2}$ test. Cost differences between CMR and CA during follow-up were assessed by two-way ANOVA. Survival was analyzed using Kaplan-Meier and Cox models. A value of $p<0.05$ was considered statistically significant.

Propensity scores were computed by binary logistic regression with diagnostic path assignment as an outcome variable and age, gender, angina pectoris, CV risk factors and cardiac medications as covariates. A 1:2 nearest neighbor matching algorithm with a caliper of 0.2 of the standard deviation of the logit of the propensity score was chosen to achieve highest possible representativeness and precision. As $20 \%$ of the CMR and $50 \%$ of the CA patients did not meet the matching criteria, they were discarded from the final analysis (Supplement, Figure S1) yielding a final study population of 502 patients. Residual imbalances of covariates after matching were assessed by univariate tests. The largest remaining standardized difference (Cohen's $d$ ) was treatment with statins $(d=-$ 0.09; see supplement, Figure S2). The overall $\chi^{2}$ balance test was not significant $\left(\chi^{2}=4.7, p=0.968\right)$ and the relative multivariate imbalance L1 measure remained unchanged in the matched sample $(0.99$ before and after matching), both indicating that matching was successful and improved the overall balance.

\section{Results}

Two hundred and nine from 502 patients with sCAD underwent initial CMR imaging (CMR group). In 14 CMR patients with negative test results (10\% of all negatives) and in 45 CMR patients with positive test results (74\% of all positives) CA was performed. The control group (CA group) comprised 293 patients. Diagnosis of sCAD was functional (exercise-induced wall motion abnormality) in the CMR group and morphological (angiographic stenosis) in the CA group. These different diagnostic modalities resulted in a lower prevalence of CAD in the CMR group (CMR: $29 \%$ vs. CA: $44 \%, p<0.001$ ).

The anthropomorphic and clinical characteristics of the CMR and CA groups did not differ significantly after propensity score matching. The patients' ages and ejection 
Table 1 Baseline characteristics of the study population

\begin{tabular}{|c|c|c|c|}
\hline & $\begin{array}{l}\text { CMR } \\
(N=209)\end{array}$ & $\begin{array}{l}\mathrm{CA} \\
(N=293)\end{array}$ & $P$ \\
\hline Age (years) & $60 \pm 9.6$ & $62 \pm 10.5$ & 0.200 \\
\hline \multicolumn{4}{|l|}{ Gender $(\%)$} \\
\hline Male & 57 & 59 & \multirow[t]{2}{*}{0.63} \\
\hline Female & 43 & 41 & \\
\hline LV ejection fraction $(\%)$ & $59 \pm 5.5$ & $59 \pm 5.0$ & 0.453 \\
\hline \multicolumn{4}{|l|}{ Angina pectoris (\%) } \\
\hline CCS I & 27 & 24 & \multirow[t]{4}{*}{0.715} \\
\hline CCS II & 27 & 25 & \\
\hline CCS III & 6 & 6 & \\
\hline CCS IV & 1 & 0 & \\
\hline Diabetes mellitus (\%) & 14 & 17 & 0.333 \\
\hline Hypertension (\%) & 72 & 78 & 0.122 \\
\hline Hyperlipidemia (\%) & 57 & 62 & 0.255 \\
\hline Smoking (\%) & 35 & 30 & 0.215 \\
\hline Framingham score & $8 \pm 2.9$ & $9 \pm 3.1$ & 0.214 \\
\hline PROCAM score & $37 \pm 11.6$ & $38 \pm 12.1$ & 0.261 \\
\hline ACE inhibitors (\%) & 57 & 57 & 0.990 \\
\hline$\beta$-blockers $(\%)$ & 44 & 51 & 0.139 \\
\hline $\begin{array}{l}\text { Calcium channel blockers } \\
(\%)\end{array}$ & 16 & 18 & 0.530 \\
\hline Statins $(\%)$ & 35 & 45 & 0.023 \\
\hline
\end{tabular}

$C M R$ cardiac magnetic resonance, $C A$ coronary angiography, $C C S$ Canadian Cardiovascular Society, PROCAM Prospective Cardiovascular Münster Study, $A C E$ angiotensin converting enzyme

fractions were similar in both groups as was their medical therapies. The Framingham and PROCAM risk scores were also similar as were the prevalence of diabetes mellitus, hypertension, hyperlipidemia and smoking (Table 1).

CMR and CA groups differed in re-hospitalization pattern-in CMR patients predominant ambulatory follow-up was reflected by a larger number of visits to the outpatient department (CMR: $83 \%$ vs. CA: $34 \%, p=0.001$ ), whereas CA patients were more often hospitalized (CMR: $35 \%$ vs. CA: $98 \%, p=0.001)$. Death occurred infrequently in both groups (CMR: $4 \%$ vs. CA: $7 \%$, $p=0.149$; Table 2). Similar survival was observed in the CMR and CA groups particularly within the first 4 years after study inclusion ( $p=0.139$; Fig. 2a), even after adjustment for revascularization by PCI (HR 1.49, $95 \%$ CI $0.44-5.07, p=0.524$ ) or CABG (HR 0.52, $95 \%$ CI $0.19-1.44, p=0.209$ ) (Supplement, Table S1).

The CMR guided approach led to a $72 \%$ reduction in CA utilization, shortened hospital stay length (CMR: 1.22 days, $95 \%$ CI $1.19-1.73$ vs. CA: 1.74 days, $95 \%$ CI$1.26-2.08, p=0.022$ ) and produced lower total costs compared to direct CA (CMR: median 2,626€, $95 \%$-CI $2,193-3,360$ vs. CA: median $3,606 €, 95 \%$ CI 3,234-4,126 $p=0.001)$. The observed cost reduction occurred at first
Table 2 Clinical endpoints

\begin{tabular}{|c|c|c|c|}
\hline & $\begin{array}{l}\text { CMR } \\
(N=209)\end{array}$ & $\begin{array}{l}\text { CA } \\
(N=293)\end{array}$ & $P$ \\
\hline CAD (\%) & $29^{\mathrm{a}}$ & 44 & 0.001 \\
\hline PCI (\%) & 1 & 21 & $<0.001$ \\
\hline CABG $(\%)$ & 1 & 15 & $<0.001$ \\
\hline Death $(\%)$ & 4 & 7 & 0.149 \\
\hline \multicolumn{4}{|l|}{ Ambulatory profile } \\
\hline $\begin{array}{l}\text { 1-5 outpatient visits } \\
(\%)\end{array}$ & 83 & 34 & $<0.001$ \\
\hline $\begin{array}{l}\text { 5-10 outpatient visits } \\
(\%)\end{array}$ & 12 & 5 & \\
\hline $\begin{array}{l}>10 \text { outpatient visits } \\
(\%)\end{array}$ & 3 & 3 & \\
\hline \multicolumn{4}{|l|}{ Hospital profile } \\
\hline $1-5$ hospital stays $(\%)$ & 35 & 98 & $<0.001$ \\
\hline$>5$ hospital stays $(\%)$ & 1 & 2 & \\
\hline
\end{tabular}

$C M R$ cardiac magnetic resonance, $C A$ coronary angiography, $C A D$ coronary artery disease, $P C I$ percutaneous coronary intervention, $C A G B$ coronary artery bypass grafting

" Diagnosis of "CAD" is either functional (exercise-induced wall motion abnormality) in the CMR group or morphological (angiographic stenosis) in the CA group

hospital admission and was maintained at follow-up (Fig. 2b). As suggested by micro-costing data analysis, the increased total costs in the CA group were mainly driven by costs in the cardiology ward and the catheterization laboratory. Differences in costs related to surgery (operating theater, anesthesia, ICU) did not achieve significance possibly due to the small number of CABG procedures. Staff costs and costs allocated for materials and infrastructure were significantly higher in the CA group (Table 3).

Comparative cost-effectiveness analysis between CMR and CA showed that the use of CMR was associated with a significant reduction in healthcare costs at similar clinical effectiveness (Fig. 2c). Further ICER indicated that there were $12,466 €$ cost savings per life year in favor of the CMR-based approach.

\section{Discussion}

In summary, DCMR-guided catheterization in patients at intermediate risk for CAD was at least as effective as direct catheterization in terms of survival and more cost-effective in terms of a substantial contribution margin to cover a part of the CMR costs. As myocardial infarction was not considered as an endpoint the prognostic value regarding ischemic events needs further corroboration. DCMR-guided catheterization was shown to be effective in terms of event-free survival during intermediate [19-21] and long- 
Fig. 2 a Long-term survival of CMR and CA patients. Survival probability (depicted on the $x$ axis) was cut at 0.6 to visually improve curve's resolution. The survival difference between CMR and CA was not significant. b Temporal dependence of diagnostic path assignment on cost progression. The cost medians with their corresponding $95 \%$ confidence intervals are provided for CMR and CA. During late follow-up ( $\geq 2$ years) due to sparse data pooled cost estimates (derived from pooled cost data of the years 2006-2008) had to be calculated and are depicted as dashed line. c Cost-

effectiveness of CMR compared with CA. Median relative differences (see "Methods" for details) with their corresponding $95 \%$ confidence intervals are provided. Pairwise comparison of CMR with CA revealed significant lower overall costs in CMR at similar clinical effectiveness
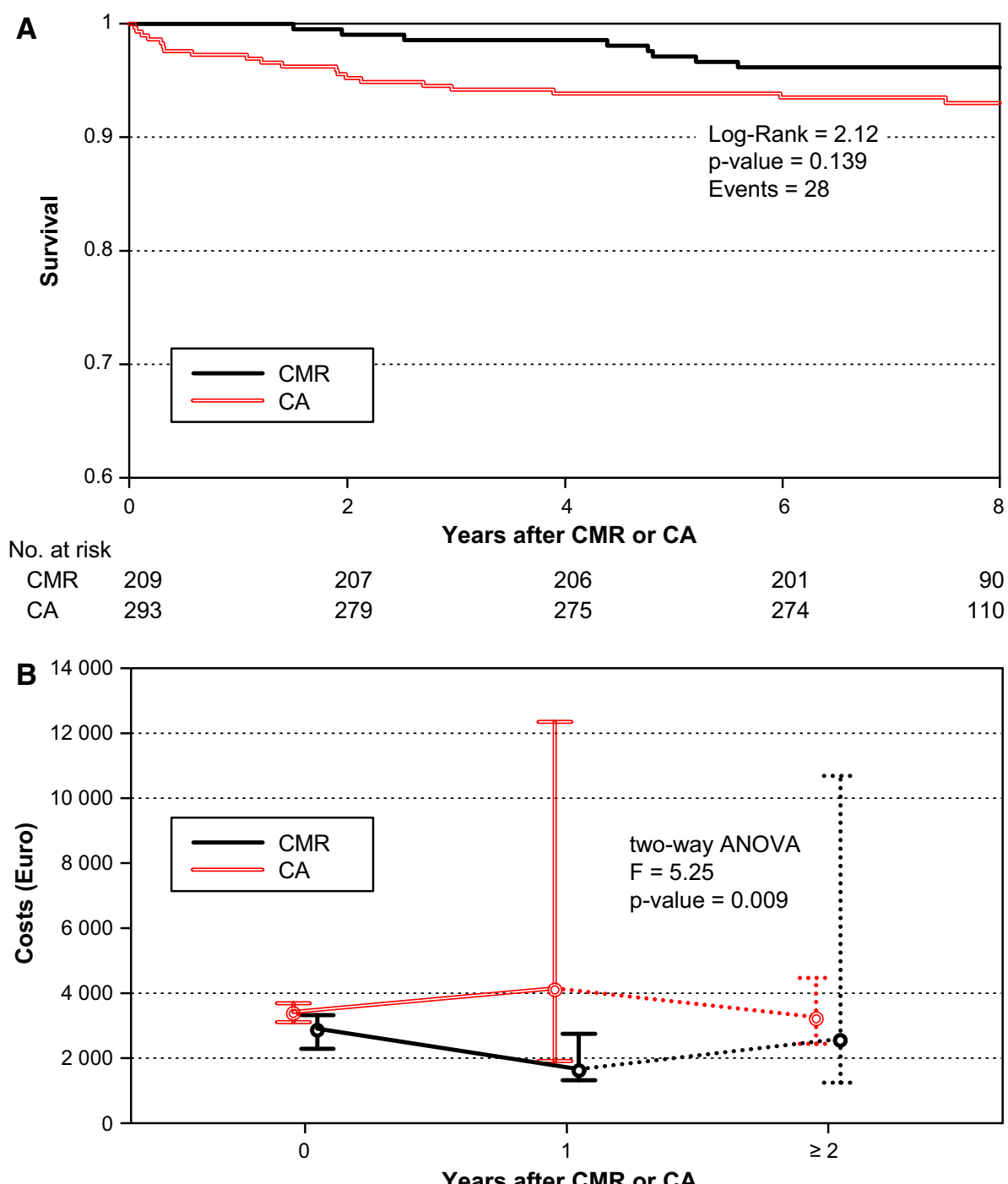

No. available pts.

$\begin{array}{llll}\text { CMR } & 29 & 10 & 13 \\ \text { CA } & 170 & 12 & 26\end{array}$

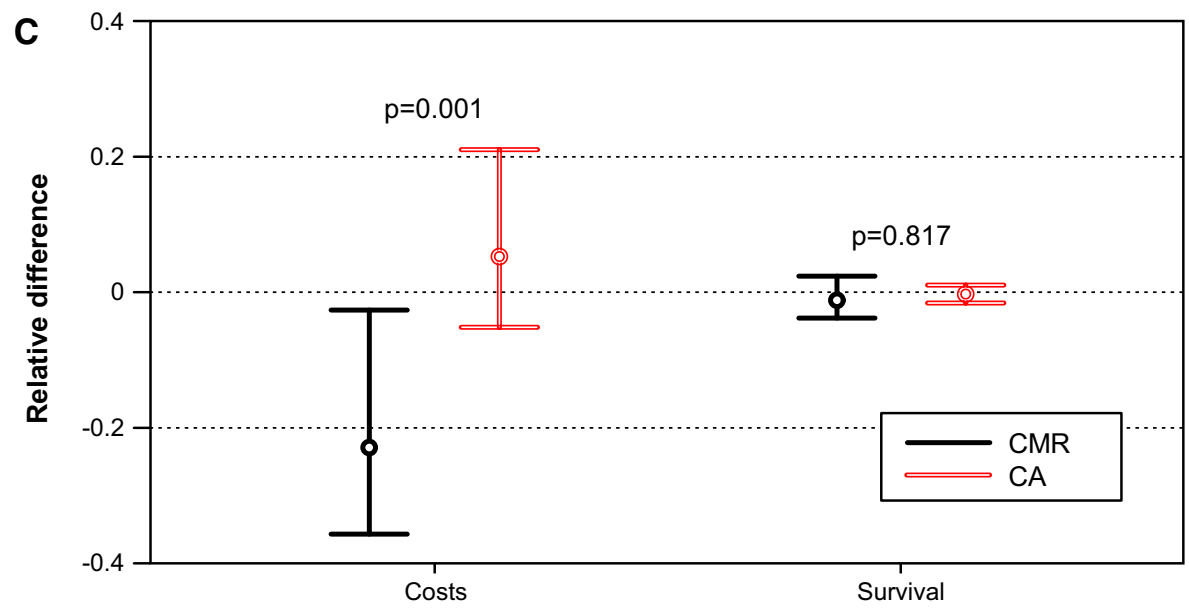


Table 3 Costs endpoints

\begin{tabular}{llll}
\hline & CMR $(N=48)$ & CA $(N=181)$ & $P$ \\
\hline Location of costs & & & \\
Cardiology ward $(€)$ & $1,337(1,024-1,420)$ & $1,432(1,389-1,772)$ & 0.002 \\
Catheterization laboratory $(€)$ & $1,016(864-1,535)$ & $1,308(1,208-1,542)$ & 0.021 \\
Operating room $(€)$ & $4,918(3,691-6,145)$ & $6,633(5,420-8,788)$ & 0.257 \\
Anesthesia/ICU $(€)$ & $1,250(1,142-2,306)$ & $2,192(1,645-2,692)$ & 0.145 \\
Laboratory medicine $(€)$ & $105(61-121)$ & $124(119-142)$ & 0.001 \\
Radiology $(€)$ & $376(149-710)$ & $351(238-487)$ & 0.921 \\
Other $(€)$ & $301(24-434)$ & $172(126-265)$ & 0.631 \\
Type of costs & & & $<0.001$ \\
Staff $(€)$ & $353(305-397)$ & $462(423-509)$ & $<0.001$ \\
Materials $(€)$ & $200(165-212)$ & $252(225-261)$ & $<0.001$ \\
Infrastructure $(€)$ & $492(436-583)$ & $674(622-719)$ & \\
\hline
\end{tabular}

term [6-8] follow-up in previous studies. Nevertheless, repeated CMR may be recommended after 3 years based on increasing event rates [7]. Comparative effectiveness is sustained during a median follow-up of more than 6 years.

Diagnostic performance of CMR in terms of reclassification of probability of CAD is not an issue in this study [14]. Anyhow, a recent editorial [22] comments on the pitfalls of substituting true diagnosis of functionally significant CAD by gold-standards. The low prevalence of CAD in the cohort reduces the sensitivity of both diagnostic tests (CMR and angiography) and compares well with findings in routine patients [15]. The discrepancy found between functional and morphologic diagnosis of CAD is partially explained by the lack of functional impact of many borderline coronary lesions. An estimate of the rate of functional significant stenosis is given by the rate of interventions multiplied by a factor of 0.63 which is the fraction of functionally significant stenosis in the FAME trial [23]. Finally, the surprisingly low rate of angiographic CAD in patients with positive CMR is not only due to a low prevalence of CAD but also to a very conservative trade-off between sensitivity and specificity in diagnosis (see supplement).

The main cost driver in the CA group was a high rate of catheterizations ruling out significant stenosis. Hospital stays were longer in the CA group and thus costs per patient stay, incurred at the cardiology ward, were increased. The increased costs located at the catheterization laboratory are probably related to an increased rate of PCIs in the CA group. The use of stents in different arms of the FAME trial [23] supports the hypothesis that the lack of information on the functional impact of a lesion may increase the propensity of interventional cardiologists to perform an unnecessary and potentially harmful PCI. Thus, the proof of functional relevance of stenosis is an essential requirement for an indication for revascularization. From the patient's perspective, this means that invasive interventions and the associated risk of complications might be significantly reduced using an image guided approach. A reduced rate of hospital stays and lower costs at follow-up suggest sustained cost-effectiveness and a patient-friendly ambulatory management profile of the DCMR-guided strategy in agreement with the findings in suspected acute coronary syndrome [24].

As DCMR is not reimbursed in Germany there was no cost calculation available. Moreover, the costs generated in ambulatory patients with negative test in the DCMR pathway depend on the prevalence of the disease. Thus, we decided to calculate the contribution of costs that would be available to cover partial costs of CMR for methodological reasons. In the literature, costs of CMR are generally estimated from reimbursements by the payer on a per patient basis [12, 25-27]. Downstream and secondary costs may be assumed to be lower in patients with a more ambulatory profile in spite of additional imaging costs. Our data suggest that in-hospital cost savings per patient provide a substantial contribution margin to cover imaging costs with no overall cost increase.

Recently there have been several HTA studies on DCMR-gated catheterization [12, 24-29]. However, level five HTA studies demonstrating incremental cost-effectiveness in terms of long-term outcome are not yet available. The published studies vary widely with respect to imaging modality, methodological approach, control groups and outcome measures and generally adopt the stakeholder perspective of the payer. A realistic system for evaluation of emerging technologies is challenged by conflicting needs and expectations of the variety of stakeholders, outdated and distorting incentives set by service valuation and payment, and the lack of a standardized and validated concept of value [30]. Thus, comprehensive HTA analysis should account for stakeholder interests and cost 
impact [31]. Current reimbursement policies have been shown to be associated with discordant HTA decisions in drug therapy [32]. In particular, the German reimbursement system rewards direct catheterization and discourages an appropriate use of CMR and other imaging technologies as recommended by recent guidelines [16]. Local expertise is supposed to be critical for the choice of imaging modality according to expert consensus and the outcomes presented here imply of course experience in CMR imaging and evaluation.

The International Society for Pharmacoeconomics and Outcomes Research recognizes the necessity and challenge of using secondary data sources, particularly retrospective data, in HTA and specifies principles for good research practice in this field [10]. Every new technology goes through a phase of establishment early in the life cycle. This phase is generally characterized by parallel use of the new technology and standard operating procedures and provides controlled data from the same source population. Secondary data mining and outcome research in these source populations based on a pre-specified hypothesis and statistical matching techniques addressing randomization are valuable sources of evidence beyond randomized controlled trials that are costly and sometimes hampered by discrepancy between real world and highly selected study populations. An increasing number of digital records, big data analyses and advanced statistical approaches [33] facilitate this endeavor. Our study is a single-center retrospective cohort trial based on a pre-specified hypothesis. The data are unique with respect to the duration of follow-up and availability of cost calculation. Moreover, the German Heart Institute is a high volume supraregional center and was engaged in the early validation of DCMR effectiveness [18]. Outcome differences are comparable to a multicenter analysis [7, 8]. Controlled study design, careful matching, and costs directly calculated from process times and low-level expenses assure the transferability of a contribution margin of inhospital cost saving by DCMR. Socioeconomic disparities, different reimbursement strategies, jurisdictions and trends in medical treatment strategies may be associated with larger differences in expenses for hospital stays. But, reducing hospitalizations and invasive procedures is expected to cut costs. In agreement with our findings in sCAD, Miller et al. [24] recently demonstrated the potential of DCMR to reduce hospitalizations, invasive procedures, and recurrent tests for ischemia in patients with suspected acute coronary syndrome. The conclusion of this study holds for CMR perfusion imaging, since expenses are similar and effectiveness is comparable [8]. Single photon emission tomography (SPECT) as an imaging modality demonstrated superior cost-effectiveness in the CeCAT trial 2007 [29]. Recent studies, however, found CMR to be more cost-effective than SPECT $[25,27]$.

\section{Limitations}

We did not include myocardial infarction as an event because extensive manual review of archived electrocardiograms, laboratory data and clinical records would have been necessary to comply with the uniform definition. We fully recognize this limitation. A further limitation is that we do not have data on the cause of death and angina pectoris during follow-up. In the COURAGE study [34], revascularization in patients with functionally significant SCAD had no impact on survival, but reduced angina by a small, but significant, amount that disappeared by 36 months. Thus, the large number of visits to the outpatient department is not fully explained by persistent angina in medically treated SCAD and partially related to a conservative surveillance strategy in these patients. Moreover, inclusion criteria of the COURAGE study do not match with patient selection in this retrospectively sampled cohort. All patients eventually included in the COURAGE study had catheterization. Of course, there are methodological limitations as compared to randomized controlled trials that are inherent in retrospective studies and may not be fully equalized by statistical matching. Moreover, long-term outcome and recentness of management are at odds. Regarding the cost calculation we did not consider discounting or inflation that would have affected the cost differences proportionally. Hospital cost differences were based on cost unit accounting that reflects real processes and resources used per hospitalized patient and should not be seriously affected by prices. Most of the discussed limitations concern the historical data set and not the methodology itself that is likely to profit from growing coverage of digital documentation in heath business and advanced big data mining in the future.

Acknowledgments We thank Eike Nagel and Gary Gerstenblith for their critical input, Anne Carney for editorial assistance and Lutz Bernard, Detlef Goesmann and Michelle Menzel for their technical support with data acquisition. We thank Michael Regitz for providing the micro-cost data.

\section{Conflict of interest None.}

Open Access This article is distributed under the terms of the Creative Commons Attribution License which permits any use, distribution, and reproduction in any medium, provided the original author(s) and the source are credited.

\section{References}

1. Banerjee A, Newman DR, Van den Bruel A, Heneghan C (2012) Diagnostic accuracy of exercise stress testing for coronary artery 
disease: a systematic review and meta-analysis of prospective studies. Int J Clin Pract 66(5):477-492. doi:10.1111/j.1742-1241. 2012.02900.x

2. de Jong MC, Genders TS, van Geuns RJ, Moelker A, Hunink MG (2012) Diagnostic performance of stress myocardial perfusion imaging for coronary artery disease: a systematic review and meta-analysis. Eur Radiol 22(9):1881-1895. doi:10.1007/s00330012-2434-1

3. Greenwood JP, Maredia N, Younger JF, Brown JM, Nixon J, Everett CC, Bijsterveld P, Ridgway JP, Radjenovic A, Dickinson CJ, Ball SG, Plein S (2012) Cardiovascular magnetic resonance and single-photon emission computed tomography for diagnosis of coronary heart disease (CE-MARC): a prospective trial. Lancet 379(9814):453-460. doi:10.1016/S0140-6736(11)61335-4

4. Nandalur KR, Dwamena BA, Choudhri AF, Nandalur MR, Carlos RC (2007) Diagnostic performance of stress cardiac magnetic resonance imaging in the detection of coronary artery disease: a meta-analysis. J Am Coll Cardiol 50(14):1343-1353. doi:10. 1016/j.jacc.2007.06.030

5. Charoenpanichkit C, Hundley WG (2010) The 20 year evolution of dobutamine stress cardiovascular magnetic resonance. J Cardiovasc Magn Reson 12:59. doi:10.1186/1532-429X-12-59

6. Kelle S, Chiribiri A, Vierecke J, Egnell C, Hamdan A, Jahnke C, Paetsch I, Wellnhofer E, Fleck E, Klein C, Gebker R (2011) Long-term prognostic value of dobutamine stress CMR. JACC Cardiovasc Imaging 4(2):161-172. doi:10.1016/j.jcmg.2010.11. 012

7. Kelle S, Nagel E, Voss A, Hofmann N, Gitsioudis G, Buss SJ, Chiribiri A, Wellnhofer E, Klein C, Schneeweis C, Egnell C, Vierecke J, Berger A, Giannitsis E, Fleck E, Katus HA, Korosoglou G (2013) A bi-center cardiovascular magnetic resonance prognosis study focusing on dobutamine wall motion and late gadolinium enhancement in 3,138 consecutive patients. J Am Coll Cardiol 61(22):2310-2312. doi:10.1016/j.jacc.2013.02.063

8. Lipinski MJ, McVey CM, Berger JS, Kramer CM, Salerno M (2013) Prognostic value of stress cardiac magnetic resonance imaging in patients with known or suspected coronary artery disease: a systematic review and meta-analysis. J Am Coll Cardiol 62(9):826-838. doi:10.1016/j.jacc.2013.03.080

9. Wallner PE, Konski A (2008) A changing paradigm in the study and adoption of emerging health care technologies: coverage with evidence development. J Am Coll Radiol 5(11):1125-1129. doi:10.1016/j.jacr.2008.06.008

10. Berger ML, Mamdani M, Atkins D, Johnson ML (2009) Good research practices for comparative effectiveness research: defining, reporting and interpreting nonrandomized studies of treatment effects using secondary data sources: the ISPOR good research practices for retrospective database analysis task force report-Part I. Value Health 12(8):1044-1052. doi:10.1111/j. 1524-4733.2009.00600.x

11. Goeree R, Levin L, Chandra K, Bowen JM, Blackhouse G, Tarride JE, Burke N, Bischof M, Xie F, O'Reilly D (2009) Health technology assessment and primary data collection for reducing uncertainty in decision making. J Am Coll Radiol 6(5):332-342. doi:10.1016/j.jacr.2009.01.012

12. Francis SA, Daly C, Heydari B, Abbasi S, Shah RV, Kwong RY (2013) Cost-effectiveness analysis for imaging techniques with a focus on cardiovascular magnetic resonance. J Cardiovasc Magn Reson 15:52. doi:10.1186/1532-429X-15-52

13. (2010) Cardiac magnetic resonance imaging for the diagnosis of coronary artery disease: an evidence-based analysis. Ont Health Technol Assess Ser 10 (12):1-38

14. Mark DB, Anderson JL, Brinker JA, Brophy JA, Casey DE Jr, Cross RR, Edmundowicz D, Hachamovitch R, Hlatky MA, Jacobs JE, Jaskie S, Kett KG, Malhotra V, Masoudi FA, McConnell MV, Rubin GD, Shaw LJ, Sherman ME, Stanko S,
Ward RP (2014) ACC/AHA/ASE/ASNC/HRS/IAC/Mended Hearts/NASCI/RSNA/SAIP/SCAI/SCCT/SCMR/SNMMI 2014 Health Policy Statement on use of noninvasive cardiovascular imaging: a report of the American College of Cardiology Clinical Quality Committee. J Am Coll Cardiol 63(7):698-721. doi:10. 1016/j.jacc.2013.02.002

15. Patel MR, Peterson ED, Dai D, Brennan JM, Redberg RF, Anderson HV, Brindis RG, Douglas PS (2010) Low diagnostic yield of elective coronary angiography. $N$ Engl J Med 362(10):886-895. doi:10.1056/NEJMoa0907272

16. Montalescot G, Sechtem U, Achenbach S, Andreotti F, Arden C, Budaj A, Bugiardini R, Crea F, Cuisset T, Di Mario C, Ferreira JR, Gersh BJ, Gitt AK, Hulot JS, Marx N, Opie LH, Pfisterer M, Prescott E, Ruschitzka F, Sabate M, Senior R, Taggart DP, van der Wall EE, Vrints CJ, Zamorano JL, Baumgartner H, Bax JJ, Bueno H, Dean V, Deaton C, Erol C, Fagard R, Ferrari R, Hasdai D, Hoes AW, Kirchhof P, Knuuti J, Kolh P, Lancellotti P, Linhart A, Nihoyannopoulos P, Piepoli MF, Ponikowski P, Sirnes PA, Tamargo JL, Tendera M, Torbicki A, Wijns W, Windecker S, Valgimigli M, Claeys MJ, Donner-Banzhoff N, Frank H, FunckBrentano C, Gaemperli O, Gonzalez-Juanatey JR, Hamilos M, Husted S, James SK, Kervinen K, Kristensen SD, Maggioni AP, Pries AR, Romeo F, Ryden L, Simoons ML, Steg PG, Timmis A, Yildirir A (2013) 2013 ESC guidelines on the management of stable coronary artery disease: the task force on the management of stable coronary artery disease of the European Society of Cardiology. Eur Heart J 34(38):2949-3003. doi:10.1093/eur heartj/eht296

17. Schulz-Menger J, Bluemke DA, Bremerich J, Flamm SD, Fogel MA, Friedrich MG, Kim RJ, von Knobelsdorff-Brenkenhoff F, Kramer CM, Pennell DJ, Plein S, Nagel E (2013) Standardized image interpretation and post processing in cardiovascular magnetic resonance: Society for Cardiovascular Magnetic Resonance (SCMR) board of trustees task force on standardized post processing. J Cardiovasc Magn Reson 15:35. doi:10.1186/1532429X-15-35

18. Nagel E, Lehmkuhl HB, Bocksch W, Klein C, Vogel U, Frantz E, Ellmer A, Dreysse S, Fleck E (1999) Noninvasive diagnosis of ischemia-induced wall motion abnormalities with the use of highdose dobutamine stress MRI: comparison with dobutamine stress echocardiography. Circulation 99(6):763-770

19. Hundley WG, Morgan TM, Neagle CM, Hamilton CA, Rerkpattanapipat P, Link KM (2002) Magnetic resonance imaging determination of cardiac prognosis. Circulation 106(18): 2328-2333

20. Korosoglou G, Elhmidi Y, Steen H, Schellberg D, Riedle N, Ahrens J, Lehrke S, Merten C, Lossnitzer D, Radeleff J, Zugck C, Giannitsis E, Katus HA (2010) Prognostic value of high-dose dobutamine stress magnetic resonance imaging in 1,493 consecutive patients: assessment of myocardial wall motion and perfusion. J Am Coll Cardiol 56(15):1225-1234. doi:10.1016/j.jacc. 2010.06.020

21. Yoon YE, Kitagawa K, Kato S, Ishida M, Nakajima H, Kurita T, Ito M, Sakuma H (2012) Prognostic value of coronary magnetic resonance angiography for prediction of cardiac events in patients with suspected coronary artery disease. J Am Coll Cardiol 60(22):2316-2322. doi:10.1016/j.jacc.2012.07.060

22. Plein S, Motwani M (2013) Fractional flow reserve as the reference standard for myocardial perfusion studies: fool's gold? Eur Heart J Cardiovasc Imaging 14(12):1211-1213. doi:10.1093/ ehjci/jet 110

23. Pijls NH, Fearon WF, Tonino PA, Siebert U, Ikeno F, Bornschein B, van't Veer M, Klauss V, Manoharan G, Engstrom T, Oldroyd KG, Ver Lee PN, MacCarthy PA, Bruyne B (2010) Fractional flow reserve versus angiography for guiding percutaneous coronary intervention in patients with multivessel coronary artery 
disease: 2-year follow-up of the FAME (Fractional Flow Reserve Versus Angiography for Multivessel Evaluation) study. J Am Coll Cardiol 56(3):177-184. doi:10.1016/j.jacc.2010.04.012

24. Miller CD, Case LD, Little WC, Mahler SA, Burke GL, Harper EN, Lefebvre C, Hiestand B, Hoekstra JW, Hamilton CA, Hundley WG (2013) Stress CMR reduces revascularization, hospital readmission, and recurrent cardiac testing in intermediate-risk patients with acute chest pain. JACC Cardiovasc Imaging 6(7):785-794. doi:10.1016/j.jcmg.2012.11.022

25. Boldt J, Leber AW, Bonaventura K, Sohns C, Stula M, Huppertz A, Haverkamp W, Dorenkamp M (2013) Cost-effectiveness of cardiovascular magnetic resonance and single-photon emission computed tomography for diagnosis of coronary artery disease in Germany. J Cardiovasc Magn Reson 15:30. doi:10.1186/1532429X-15-30

26. Moschetti K, Muzzarelli S, Pinget C, Wagner A, Pilz G, Wasserfallen JB, Schulz-Menger J, Nothnagel D, Dill T, Frank H, Lombardi M, Bruder O, Mahrholdt H, Schwitter J (2012) Cost evaluation of cardiovascular magnetic resonance versus coronary angiography for the diagnostic work-up of coronary artery disease: application of the European Cardiovascular Magnetic Resonance registry data to the German, United Kingdom, Swiss, and US health care systems. J Cardiovasc Magn Reson 14:35. doi:10.1186/1532-429X-14-35

27. Walker S, Girardin F, McKenna C, Ball SG, Nixon J, Plein S, Greenwood JP, Sculpher M (2013) Cost-effectiveness of cardiovascular magnetic resonance in the diagnosis of coronary heart disease: an economic evaluation using data from the CE-MARC study. Heart 99(12):873-881. doi:10.1136/heartjnl-2013-303624

28. Pilz G, Patel PA, Fell U, Ladapo JA, Rizzo JA, Fang H, Gunnarsson C, Heer T, Hoefling B (2011) Adenosine-stress cardiac magnetic resonance imaging in suspected coronary artery disease: a net cost analysis and reimbursement implications. Int $\mathrm{J}$ Cardiovasc Imaging 27(1):113-121. doi:10.1007/s10554-010-9645-9

29. Sharples L, Hughes V, Crean A, Dyer M, Buxton M, Goldsmith K, Stone D (2007) Cost-effectiveness of functional cardiac testing in the diagnosis and management of coronary artery disease: a randomised controlled trial. The CECaT trial. Health Technol Assess 11(49):iii-iv (ix-115)

30. Wallner PE, Steinberg ML, Konski AA (2011) Controversies in the adoption of new healthcare technologies. Front Radiat Ther Oncol 43:60-78. doi:10.1159/000322401

31. Mauskopf JA, Sullivan SD, Annemans L, Caro J, Mullins CD, Nuijten M, Orlewska E, Watkins J, Trueman P (2007) Principles of good practice for budget impact analysis: report of the ISPOR Task Force on good research practices-budget impact analysis. Value Health 10(5):336-347. doi:10.1111/j.1524-4733.2007. 00187.x

32. Spinner DS, Birt J, Walter JW, Bowman L, Mauskopf J, Drummond MF, Copley-Merriman C (2013) Do different clinical evidence bases lead to discordant health-technology assessment decisions? An in-depth case series across three jurisdictions. Clinicoecon Outcomes Res 5:69-85. doi:10.2147/CEOR.S39624

33. Roberts K, Rink B, Harabagiu SM (2013) A flexible framework for recognizing events, temporal expressions, and temporal relations in clinical text. J Am Med Inform Assoc 20(5):867-875. doi:10.1136/amiajnl-2013-001619

34. Weintraub WS, Spertus JA, Kolm P, Maron DJ, Zhang Z, Jurkovitz C, Zhang W, Hartigan PM, Lewis C, Veledar E, Bowen J, Dunbar SB, Deaton C, Kaufman S, O'Rourke RA, Goeree R, Barnett PG, Teo KK, Boden WE, Mancini GB (2008) Effect of PCI on quality of life in patients with stable coronary disease. N Engl J Med 359(7):677-687. doi:10.1056/NEJMoa072771 